\title{
Research on a Numerical Control Radial Feed Whirlwind Milling Device Guo-Zhe YANG ${ }^{a}$, Feng LIU ${ }^{b}$ \\ School of Mechanical Engineering, Shenyang University of Technology, Shenyang, PR China 110870 \\ ayangguozhe@sina.com, bxxys12@126.com \\ ${ }^{*}$ Corresponding author
}

Keywords: Whirlwind Milling, High Speed Machining, Numerical Control.

\begin{abstract}
The paper aimed at the problem of machining of fortified drill collar which common turning has the low efficiency. The author design a numerical control radial feed whirlwind milling device on the basis of inner whirlwind milling equipment, the device can be numerical control radial feed in machining. The device would increase the machining efficiency of parts which is same as dumbbell, and has practical significance for the machining of those workpiece.
\end{abstract}

\section{Introduction}

Production in twenty-first Century will be globalize, the competition of the international manufacturing industry will become more and more intense, which requires the manufacturing enterprises must respond quickly to the existing market demand and potential demand, with excellent performance, low price products and fast delivery. This will drive manufacturing technology towards fast, low consumption and high quality high precision. In this process, the comprehensive technology of high speed machining as industry base will play a key role. High speed machining which brings high efficiency and high accuracy is not only increases the high spindle speed, but also improve the machining efficiency and quality. The whirlwind milling can improve the machining efficiency and quality at the same time.

This design is aimed at the difficulty in machining of the fortified drill collar used by deep-sea drilling, to research a method of using whirlwind milling in the machining of fortified drill collar. The drill collar accident often occur at connection position, in order to strengthen the strength of the drill collar, the fortified drill collar is designed. But this also brought problem in the process of machining the fortified drill collar, that the fortified drill collar has the form same as dumbbell, the traditional machining method of the fortified drill collar is turning, this method has low efficiency, with whirlwind milling, the machining efficiency is equivalent to turning several times.

\section{The Structure Design of the Device}

The aim of paper is machining of variable diameter slender rod with whirlwind milling, typical example is the drill collar used by deep-sea drill, which general structure as shown Fig1.

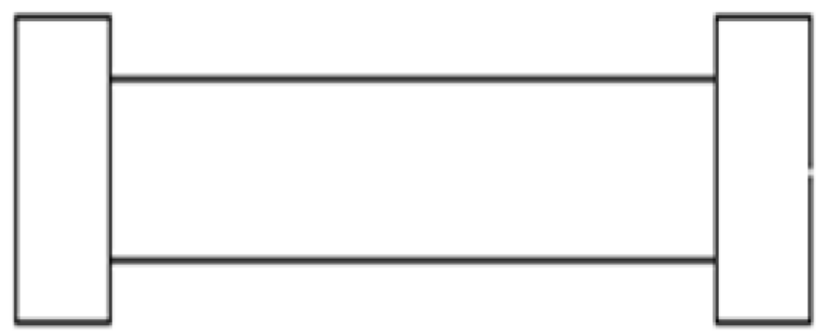

Fig.1 the fortified drill collar 
The conventional machining method of the fortified drill collar is turned step by step. This method has low processing efficiency. Using the whirlwind milling, the processing efficiency and surface quality can be improved.

But how to change the cutter diameter in the process of machining is the difficulty of this design, because must have a radial feed movement when machining. This design is change the cutting diameter by ball screw which has minor rift based on inner whirlwind milling.

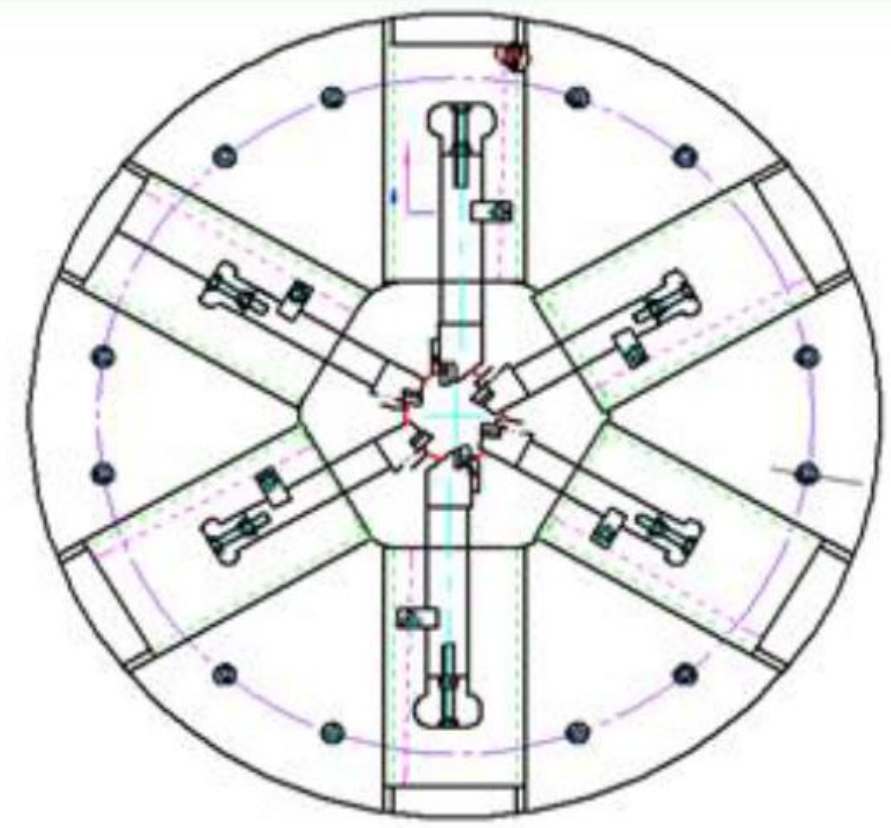

Fig.2 the tools plat

The main idea is use a servo motor to drive a large bevel gear to rotate, the large bevel gear with six bevel gear, when large bevel gear rotates, then drive the six bevel gears to rotate same time, each small bevel gear driving a ball screw, the radial feed movement of tools is reached by rotating the ball screw to drag the tool groove. Each bevel gear compensate backlash by butterfly spring to induce groove moving, prevent tool damage

This design uses the typical structure of ball screw to realize the radial feed movement, the advantage of this structure is the ball screw backlash is small, good technology, high transmission precision, so the ball screw is the most commonly used structure.

In order to realize radial feed, using two cutting off tools and four right hand tools, arrangement each tool included angle of 120 degrees, shown as Fig3. The cutting off tools and right hand tools with the minimum cutting diameter is same the cutting diameter, and end to end in axial position.

When machining, the main motor drive the tools plat rotation by the synchronous belt, then the six tools rotate around the workpiece, adjust the speed of servo motor revolution to ensure that no relative motion between the big bevel gear and six bevel gear, so that the radial position of tools does not change. When the diameter of the workpiece need to change, the six tools have the radial movement relative to the workpiece, is the so-called diameter changed. If tools stop the axial feed, but keep at a fixed speed of revolution, adjusts the speed of servo motor revolution, then there is relative motion between the big bevel gear and the six bevel gears, while the six bevel gears will rotate around the their own axis, this will drive the rotating of the ball screw to drive the radial motion of tool groove, so as to achieve the purpose of diameter changing.

\section{Study on the Control System}

The main difficulty of this task is to ensure the accurate of radial feed, namely according to the revolute speed of main motor to control the revolute speed of servo motor. To accomplish this task, the NC system control device by superimpose of electronic gear and the linear servo control. 

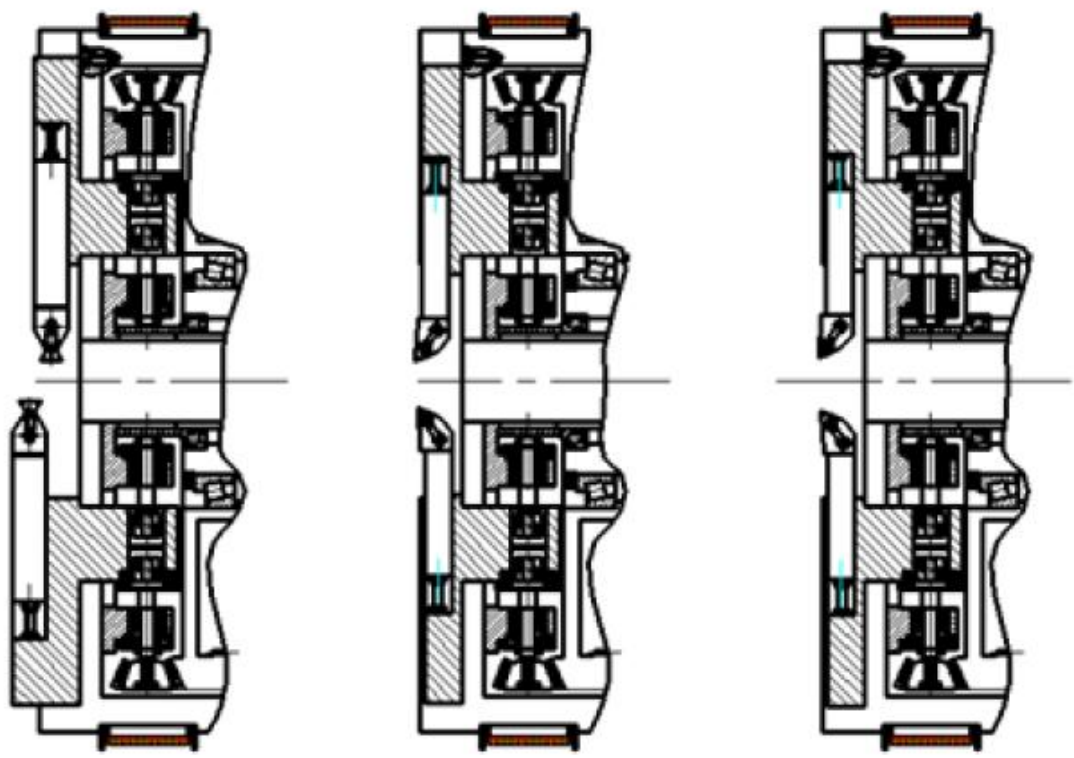

Fig. 3 the arrangement of six tools

The so-called "electronic gear" is a function used in CNC machine tool feed position control. by the instruction pulse sent from NC system, the NC system can control the feed of mobile components do not take into account the mechanical deceleration ratio and encoder pulse number, the amount of input pulse send by $\mathrm{CNC}$ system can set to any value to get the position of the mobile components.

General servo systems adjust the relationship between pulse amount and feed distance by adjusting the "electronic gear ratio" which is a unit of a pulse feed distance. Several factors of "electronic gear ratio" is encoder feedback pulse per revolution (i.e. driving motor turn to pulse, also known as the encoder resolution); mechanical transmission ratio (i.e. the servo motor shaft pinion and ring gear or gear and the bevel gear ratio); the ball screw pitch.

Have the above parameters, we can be obtained the feed distance drive by a pulse, and the number of pulses per second from the servo system determine the feed speed. According to the radial feed speed we can calculate the number of pulses to realize the radial feed, and then superimposed on the number of pulses maintain tool radial distance unchanged, it is to realize radial feed whirlwind milling electronic gear control.

\section{How to Use the Device}

When the device machine workpiece with the same diameter, the three-phase asynchronous motor drive the external tools plat through a synchronous belt, so as to drive the six tools to cut the workpiece. The external tools plat drives photoelectric encoder to rotate by another synchronous belt to obtain the revolution speed signal of external tools plat. Servo motor drive the inner tools plat through gears. CNC system control the revolution speed of servo motor through the electronic gear function to ensure that the external tools plat and the inner tools plat rotating at the same speed, then the device function is equivalent to the common whirlwind milling.

When it is need to change the diameter of the workpiece which is milling, a speed changed value which is calculated by the numerical control system electronic gear module is superimposed on the control signal of CNC system, so revolution speed of the external tools plat is not the same, there is a difference between the two speed, the speed difference is radial feed speed. Through the drive bevel gear pair, the six ball screws drive tool grooves radial motion thus realizing the radial feed whirling milling. The speed and direction of the tool grooves is controlled by the speed difference, changing the value and the direction of speed difference, CNC system achieves radial feed whirlwind milling. 


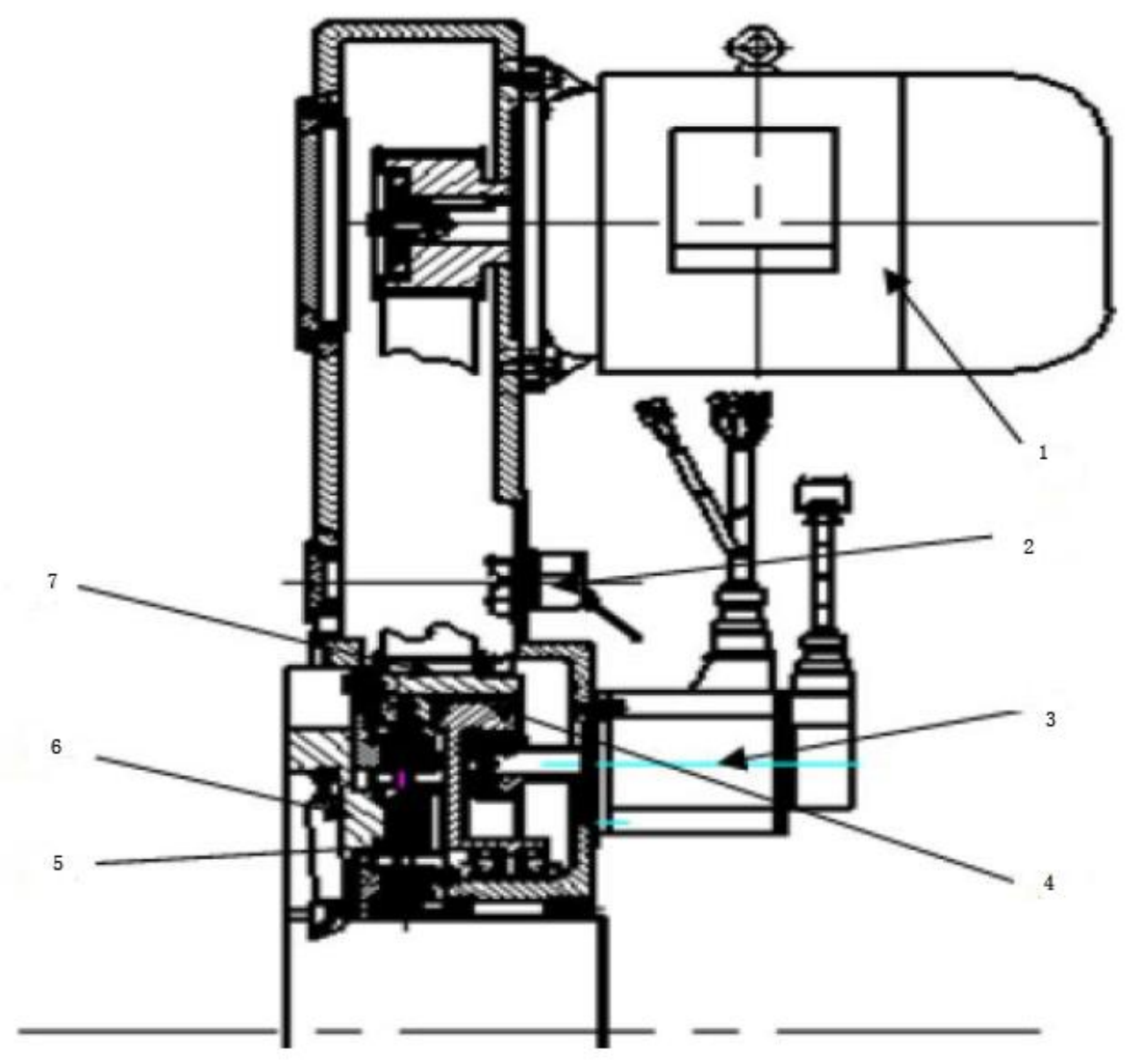

Fig.4 structure of the radial feed whirlwind milling device

1- three-phase asynchronous motor, 2- photoelectric encoder, 3- servo motor, 4-the inner tools plat, 5-tool groove, 6-ball screw, 7-the external tools plat

\section{Conclusion}

Aimed at the problem in parts machining, such as fortified drill collar, a whirlwind milling which can feed in radial direction was designed. The whirlwind milling has two tools plats drive by different motor, inner tools plat drive by a servo motor, external tools plat drive by a three-phase asynchronous motor, ensure that the inner tools plat and external tools plat is asynchronous rotation can realize the ordinary whirlwind milling. Speed difference between the inner tools plat and external tools plat realize the radial feed. Speed of the inner tools plat head beyond or behind speed of external tools plat can realize radial feed or retreat. Using the method of electronic gear function of CNC system adjusts the speed difference between the inner tools plat and external tools plat to control the speed of radial feed or retreat.

\section{References}

[1] G Z Yang, F Liu, H B Lin. Research on an Embedded Sevro Control system of micro-EDM. Applied Mechanics and Materials. vol 120, 2011, p.573-577

[2] Han Fuzhu, Wachi Shinya, Kunieda Masanori. Improvement of Machining Characteristics of Micro-EDM Using Transistor Type Isopulse Generator and Servo Feed Control. Precision Engineering, 2004, p.378-385.

[3] Matsuhara Y, Obara H. Study on High Finish Machining in Wire EDM. Journal of Electrical machining Technology, 2004, p.28:19-22. 
[4] Naotake M, Hiromichi M, Nagao S. Development of an Electrical Discharge Drilling Device by Using a New Method for Direct Drive of Electrode. Journal of the Japan Society of Precision Engineering, 1992, p.2063-2068.

[5] Katsushi F, Naotake M, Toshiro H. Direct Drive Mechanism of EDM Electrode Utilizing Elliptical Movement. Journal of the Japan Society of Precision Engineering, 1995, p.672-676.

[6] Li Y, Guo M, Zhou Z Y, et al. Micro Electro Discharge Machine with an Inchworm Type of Micro Feed Mechanism. Journal of the International Societies for Precision Engineering and Nanotechnology, (2002), pp.7-14 